\title{
FACTORS INFLUENCING THE NON-ADOPTION OF GREEN BUILDING SPECIFICATIONS IN KLANG VALLEY MALAYSIA
}

\author{
Mohd Hilmi Izwan Abd-Rahim¹, Tien-Choon Toh ${ }^{1, *}$, Yoke-Lian Lew ${ }^{1}$, See-Jie Ng${ }^{1}$, Kai-Chen Goh², Sulzakimin Mohamed², Nadzirah \\ Zainordin', Mei-Ye Kho ${ }^{4}$ \\ ${ }^{1}$ Lee Kong Chian Faculty of Engineering and Science, Universiti Tunku Abdul Rahman, Kajang, Malaysia \\ ${ }^{2}$ Faculty of Technology Management and Business, Universiti Tun Hussein Onn Malaysia, Batu Pahat, Malaysia \\ ${ }^{3}$ Faculty of Engineering, Built Environment and Information Technology, SEGi University, Petaling Jaya, Malaysia \\ ${ }^{4}$ Faculty of Built Environment, Universiti Malaya, Kuala Lumpur, Malaysia
}

ABSTRACT - Construction industry plays a pivotal role in driving economic growth and bringing more job opportunities. However, construction activities also bring adverse pollutions to the environment. Therefore, the adoption of green building specifications is crucial to mitigate these pollutions by promoting efficient resources utilisation and environmental-friendly practices. Thus, the purpose of this study is to investigate the factors influencing the non-adoption of green building specifications in Klang Valley Malaysia and to examine the underlying structure caused by the latent factors. In addition, this study is conducted to investigate the effects caused by the nonadoption of green building specifications. This study adopted a quantitative research approach that utilises online questionnaire to collect quantitative data from the respondents. According to the results, the most influential factor is "Unwillingness to change the conventional way", while the least influential factor is "Conflicts with aesthetic issues". Among the three effects studied, "Worsen soil pollution" is the most significant effect. Next, the factors are categorised into five factor groupings through factor analysis, namely, Green technology related-factor, Governmental related-factor, Economic related-factor, Public awareness and behaviour related-factor and Corporate relatedfactor. Based on the interpretation of the results, "Unwillingness to change conventional way" is the highest ranked influential factor, which may be due to the habitual thinking of construction stakeholders in remaining their existing business practices. "Conflicts with aesthetic issues" is the least ranked factor because green features actually do not downgrade but enhancing the appearance of the buildings, for instance, Energy Commission Diamond Building in Putrajaya has a good physical appearance indeed. In conclusion, this study has ranked the factors to show their degrees of significance towards the non-adoption of green building specifications. Besides that, the factors are categorised into five factor groupings and the differences among the factor groupings are also studied.
ARTICLE HISTORY

Received: 4-3-2020

Accepted: 12-5-2020

KEYWORDS

Non-adoption;

Green building specifications; Klang Valley Malaysia

\section{INTRODUCTION}

It is undeniable that construction industry has an adverse impact on natural environment, in accordance to statistics and various researches. This is because construction industry is a resource-intensive industry, which it is accounted for a great proportion of resource consumption and environmental pollution (Wang et al., 2018b). Therefore, the adoption of green building technology is a global concern nowadays as it plays a pivotal role in mitigating the profound impacts caused by construction industry on environment.

Green buildings are defined as structures that are efficient resource utilisation and environmental-friendly throughout a whole building's lifecycle (Hwang et al., 2017b). The specifications installed in green buildings are also defined as systems or appliances that promote energy-efficiency by reducing consumption of resources and utilising alternative recycled materials in lieu of non-renewable resources (Wang et al., 2018b). There are several statistics indicating the massive consumption or usage of resources in other countries due to development of construction industry. In China, Wang et al. (2018a) stated that forty percent steel and cement in the world, amounted to 2 billion $\mathrm{m}^{3}$ will be used by new buildings. They also stated that China is the second largest building energy user in the world. In addition, according to US Green Building Council, it showed that buildings in developed countries such as United States has consumed sixtyeight percent of electricity, eighty-eight percent of portable water and forty percent of raw materials as well as contributed to 20 percent of solid waste streams (Darko et al., 2017).

There are several previous studies have been conducted in accordance to the adoption of green buildings specifications in construction industry. For instance, Wang et al. (2018a) studied and evaluated the factors for adoption of green building specifications in China. They found that the six factors that contribute to the adoption were green technology, awareness 
and attitude, policies and regulations, market and economics. In addition, Simpeh and Smallwood (2015) also conducted similar study to investigate the factors influencing growth of green building in the South African construction industry. Based on their studies, they found that lack of incentives for promoting green building and inadequate cost data for green buildings are two major factors that affect the growth of green building. Besides that, Hwang et al. (2017b) also conducted study on the factors affecting productivity in green building construction projects in Singapore and they identified and categorised the factors into five group factors, which are project factors, manpower factors, management factors, technical factors and external factors.

Based on the above studies, it can be inferred that the earlier studies focused on the factors influencing adoption of green building in construction industry in other countries instead of Malaysia. Nevertheless, there were studies conducted to identify the factors affecting green building demand in Malaysia, but the studies were limited and scope covered was broad. Hence, there was a risk that the previous studies failed to address the actual situations that happen in Malaysia. In addition, the previous studies also concentrated on the factors to the green building adoption, but they did not take into consideration of the relationship between the various construction stakeholders and the factors. Hence, this study decides to investigate the factors influencing the non-adoption of green building specifications in Klang Valley, Malaysia and attempts to take an integrated approach to analyse the perspectives of different construction stakeholders on the factors. This study is important as it investigates the factors influencing the non-adoption of green building specifications in a specific area which can provide a clearer point of view of the related stakeholders within the area, which is Klang Valley, Malaysia. In addition, it also shows correlations between the factors through factor analysis and investigates the effects caused by the non-adoption of green building specifications. Lastly, it provides a comprehensive analysis on the relationship between the construction industry stakeholders and the variables in determining the various parties' perspectives and interests in this topic.

\section{LITERATURE REVIEW}

\section{Introduction to Green Building Specifications}

Green building, as stated by Darko and Chan (2016), is a building that, in its design and construction or operation, mitigates or eradicates negative impacts and provide positive impacts to natural environment and climate. According to the U.S Office of Federal Environmental Executive, "green building' is also defined as the practices of increasing the efficiency of a building or site in resources utilisation such as energy, water and materials, thus reducing building impacts on human health and the environment". In addition, Wang et al. (2018b) also stated that in terms of green buildings, people remark that "the construction and use of buildings are environmentally responsible and improve the effective utilisation of energy efficiency during the life cycle of entire construction project." Besides that, Hwang et al. (2017a) also defined green building specifications as a series of standards, guidelines or codes that related to the green constructions by emphasising on the environmental friendliness, economics and social development. The definition of green building specifications also supported by Lam et al. (2009) in their studies, stating that it is a specification framework adopting a database of preference environmental-friendly products. Hence, after considering varied definitions by institutions and previous studies, green building specifications could be defined as a system that comprises green technology, codes, practices and standards that related to green construction in order to improve social, economic and environmental conditions for present and future generations.

Green building specifications have developed drastically over the last decade. This is supported by Darko et al. (2017) in their studies, stating that green technology such as green roof, solar water heaters, grey water treatment systems and other related green technology have gained broad acceptance by the construction stakeholders. In terms of codes and regulations, the improvements could also be seen from the establishment of BREEAM (Building Research Establishment Environmental Assessment Method) by UK in 1990, followed by the establishment of LEED (Leadership in Energy and Environmental Design) green building rating system by U.S. Green Building Council (USGBC) in 1998. These recognised assessment systems are used to evaluate and certify the performance of a green building from the aspect of energy efficiency, resources utilisation, building effects on occupants' health and other relevant considerations.

In Malaysia, the green building specifications issue has also gained the concern from interest parties such as corporates, construction parties and end users. This could be seen from the establishment of Green Building Index (GBI) system in Malaysia, which is the first local rating system developed jointly by Association of Consulting Engineers Malaysia (ACEM) and the Malaysian Institute of Architects (PAM) in 2009. Similar to others, GBI also served to evaluate the green construction in terms of six areas which are energy efficiency, materials and resources, water efficiency, sustainable site planning and management, indoor environment quality and innovation. In addition, Malaysia also took initiatives in encouraging adoption of green building among construction stakeholders such as the enactment of National Green Technology Policy and Malaysia Green Building Confederation (MGBC). Malaysia government also demonstrated its commitment by constructing an iconic green building in Putrajaya, known as the diamond building.

\section{Factors Influencing the Non-Adoption of Green Building Specifications}

The factors or barriers influencing the non-adoption of green building specifications in Klang Valley, Malaysia that studied in this research are referred from previous researches from different countries and regions. The factors are listed in Table 1, with their respective references. 
Table 1 . Factors influencing the non-adoption of green building specifications

\begin{tabular}{cl}
\hline Code & Factors \\
\hline F01 & Higher initial cost of GB adoption \\
F02 & $\begin{array}{l}\text { Higher cost pressure without the } \\
\text { of economies of scale }\end{array}$ \\
F03 & $\begin{array}{l}\text { Lack of market demand on green } \\
\text { buildings }\end{array}$ \\
F04 & $\begin{array}{l}\text { Limited support from the senior } \\
\text { management for GS adoptions }\end{array}$
\end{tabular}

F05 Lack of local R\&D institutes and services

F06 Unfamiliarity with green technologies

F08 Poor reliability and quality of specifications

F10 Lack of governmental regulations and incentives

Inadequate green material supply chain

F12 Lack of benchmarking system

F13 Lack of technology and testing institutes for green specifications

F14 Lack of marketisation of specifications

\section{Sources}

Wang et al. (2018a), Darko et al. (2018), Shi et al. (2013), Hwang (2018), Hwang et al. (2017b), Lam et al. (2009), Samari et al. (2013), Chan et al. (2016)

Wang et al. (2018a), Darko et al. (2017), Hwang (2018), Hwang et al. (2017b), Elias and Chong (2015, Samari et al. (2013), Chan et al. (2016)

Wang et al. (2018a), Darko et al. (2018), Hwang (2018), Hwang et al. (2017b), Elias and Chong (2015), Samari et al. (2013), Potbhare et al. (2009), Chan et al. (2016)

Wang et al. (2018a), Darko et al. (2018), Shi et al. (2013), Hwang (2018), Hwang et al. (2017b), Elias and Chong (2015), Lam et al. (2009), Potbhare et al. (2009), Chan et al. (2016)

Wang et al. (2018a), Simpeh and Smallwood (2015), Darko et al. (2018), Shi et al. (2013), Elias and Chong (2015), Samari et al. (2013), Potbhare et al. (2009), Chan et al. (2016) Wang et al. (2018a), Simpeh and Smallwood (2015), Darko et al. (2018), Shi et al. (2013), Hwang (2018), Hwang et al. (2017b), Elias and Chong (2015), Lam et al. (2009), Samari et al. (2013), Potbhare et al. (2009), Chan et al. (2016)

Wang et al. (2018a), Shi et al. (2013), Lam et al. (2009)

Wang et al. (2018a), Simpeh and Smallwood (2015), Darko et al. (2018), Shi et al. (2013), Elias and Chong (2015), Lam et al. (2009), Samari et al. (2013), Potbhare et al. (2009), Chan et al. (2016)

Wang et al. (2018a), Darko et al. (2018), Hwang (2018), Hwang et al. (2017b), Samari et al. (2013), Potbhare et al. (2009), Chan et al. (2016)

Wang et al. (2018a), Simpeh and Smallwood (2015), Darko et al. (2018), Shi et al. (2013), Hwang (2018), Hwang et al. (2017b), Elias and Chong (2015), Samari et al. (2013), Potbhare et al. (2009), Chan et al. (2016)

Wang et al. (2018a), Simpeh and Smallwood (2015), Darko et al. (2018), Shi et al. (2013), Lam et al. (2009), Samari et al. (2013), Potbhare et al. (2009), Chan et al. (2016) Wang et al. (2018a), Darko et al. (2018), Hwang (2018), Hwang et al. (2017b), Samari et al. (2013), Potbhare et al. (2009), Chan et al. (2016)

Wang et al. (2018a), Simpeh and Smallwood (2015), Darko et al. (2018), Shi et al. (2013), Elias and Chong (2015), Samari et al. (2013), Potbhare et al. (2009), Chan et al. (2016) Wang et al. (2018a), Hwang et al. (2017b), Lam et al. (2009), Samari et al. (2013), Chan et al. (2016) 
F16

Unwillingness to change the conventional way

F17

Low public awareness of environmental issues

F18 Lack of technology innovation
Wang et al. (2018a), Simpeh and Smallwood (2015), Darko et al. (2018), Shi et al. (2013), Hwang (2018), Hwang et al. (2017b), Elias and Chong (2015), Lam et al. (2009), Samari et al. (2013), Potbhare et al. (2009), Chan et al. (2016)

Wang et al. (2018a), Simpeh and Smallwood (2015), Darko et al. (2018), Hwang (2018), Hwang et al. (2017b), Elias and Chong (2015), Lam et al. (2009), Potbhare et al. (2009), Chan et al. (2016)

Wang et al. (2018a), Darko et al. (2018), Shi et al. (2013), Hwang (2018), Hwang et al. (2017b), Elias and Chong (2015), Samari et al. (2013), Potbhare et al. (2009), Chan et al. (2016)

Wang et al. (2018a), Simpeh and Smallwood (2015), Darko et al. (2018), Shi et al. (2013), Elias and Chong (2015), Samari et al. (2013), Potbhare et al. (2009), Chan et al. (2016)

\section{Theoretical Framework}

A theoretical framework is useful to show theory of this research study. Hence,a research framework has been introduced in this research to show the relationship between the variables and the topic studied in this research. Figure 1 shows the factors or barriers influencing the non-adoption of green building specifications in Klang Valley Malaysia and the potential effects caused by the non-adoption.

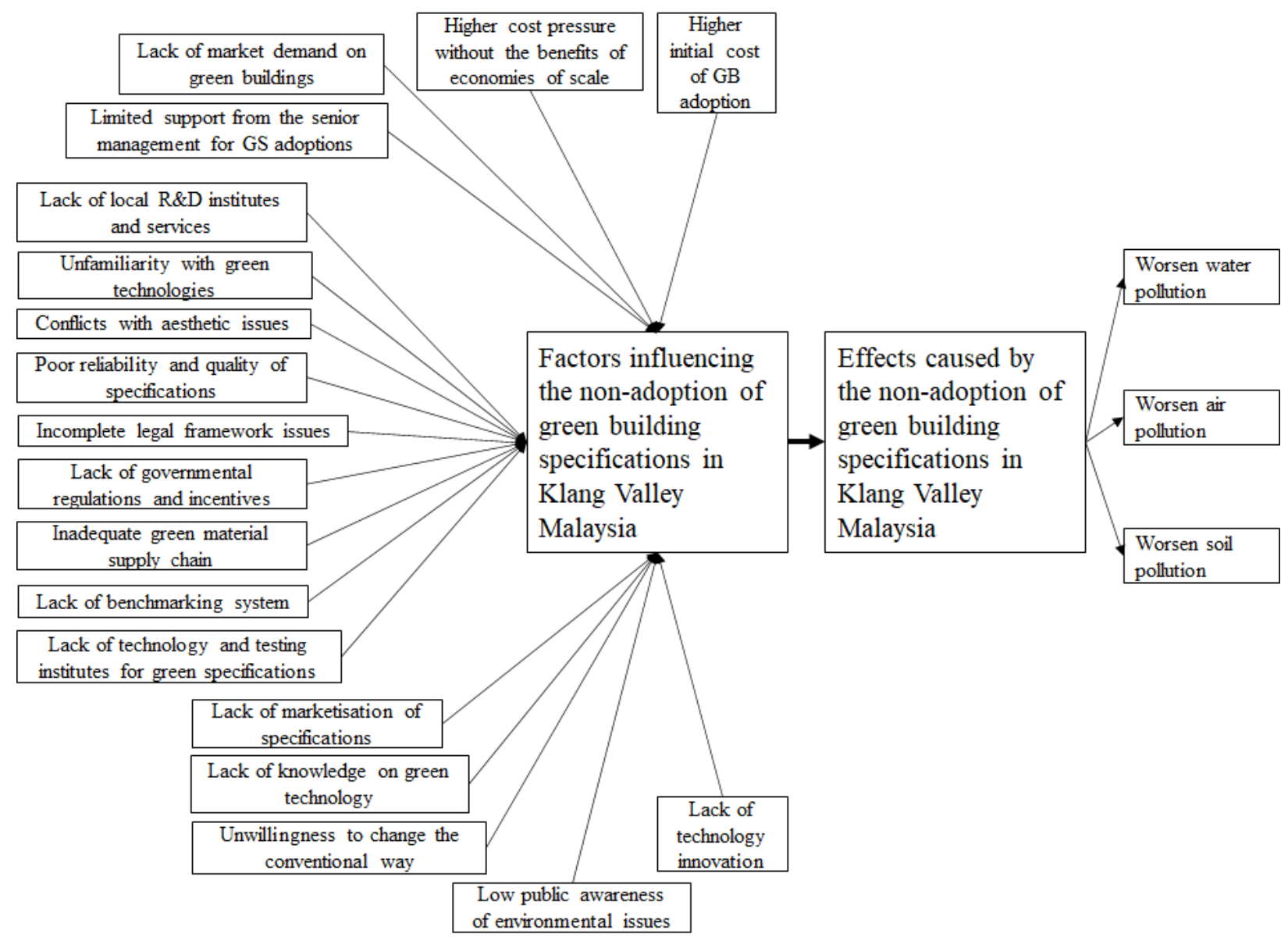

Figure 1. The theoretical framework of this research study 


\section{METHODOLOGY}

\section{Data Collection}

In this research, quantitative analysis was implemented to gather opinions from 180 selected respondents of this study, who were construction stakeholders or practitioners that currently working or in charge of any construction projects in Klang Valley Malaysia. Thus, a questionnaire was designed and evaluated. Pilot study was conducted to refine and revise the questionnaire as well. The questionnaire comprised of 4 sections, which are Introduction, Section A, Section B and Section C. The first section, Introduction explained about the purpose of this questionnaire, title of this research study and contact details of author. The second section, Section A designed to gather demographic information from respondents, including the types of organizations they belong to currently, their job positions and working experiences. Within the third section, Section B, the respondents were asked to rate the level of significance on all the 18 factors influencing the non-adoption of green building specification, from the lowest rate "Strongly Disagree" to the highest rate "Strongly Agree", ranging from scale 1 to 5. While for the last section, Section C, respondents were asked to assess the degree of significance on the 3 effects caused by the non-adoption of green building specifications, similar to Section B. The assessments in Section B and Section C were made using five-point Likert scale. The questionnaire was distributed to selected respondents through online social platform.

Among the 180 respondents, from the aspect of organizations types, there were total 71 respondents from developerfirm background, 51 respondents from construction consultant-firm background and others were from contractor-firm. In terms of job positions, $28 \%$ of the respondents were managerial staff, which included positions such as Managing Director, Director, Senior Manager, Manager and Assistant Manager. While $72 \%$ were executive staff that included Executive, Architect, Engineer, Quantity Surveyor and Supervisor. With regards to the working experience of the respondents, $43 \%$ of the respondents were Junior staff, who have less than 5 years working experience, while $57 \%$ of the respondents were Senior staff, who have 5 years or more years working experience. The distribution of the respondents were deemed reasonable, considering the nature of the construction industry in Malaysia.

\section{Data Analysis}

The mean ranking analysis and factor analysis were implemented to analyse the factors influencing the non-adoption of green specifications and effects caused by the non-adoption in this study, through application PASW Statistics 18 . The mean ranking analysis was conducted by using the five-point Likert scale $(1=$ Strongly Disagree, $2=$ Disagree, $3=$ Neutral, $4=$ Agree, 5 = Strongly Agree) were used to calculate the mean scores of each variable, which showed the relative importance level of each variable. Factor analysis is a statistical technique which is used to find clusters of the related variables. In this research study, the factor analysis was conducted to explore the latent relationship among the factors and to extract the factors to few groupings.

Besides that, parametric tests were applied in this research study as well, which are independent samples t-test and one-way ANOVA. These two tests were used to analyse the statistically significant differences in mean scores of the variables among different groups of respondents, in terms of their job positions, working experiences and types of organisations they belong. The significance value or p-value of the tests that are less than 0.05 indicated there is a statistically significant difference between the mean scores of the different groups of respondents.

\section{FINDINGS AND DISCUSSION}

\section{Rank Analysis}

Talble 2. Mean ranking analysis of the barriers (between managerial staff and executive staff)

\begin{tabular}{ccccccccc}
\hline \multirow{2}{*}{ Code } & \multirow{2}{*}{\begin{tabular}{c} 
All Respondents \\
\cline { 2 - 9 }
\end{tabular}} & \multicolumn{2}{c}{$\begin{array}{c}\text { Managerial Staff } \\
\text { (MS) }\end{array}$} & $\begin{array}{c}\text { Executive Staff } \\
\text { (ES) }\end{array}$ & $\begin{array}{c}\text { Independent } \\
\text { Samples t-Test }\end{array}$ & $\begin{array}{c}\text { Mean } \\
\text { Difference }\end{array}$ \\
\hline Mean & Rank & Mean & Rank & Mean & Rank & p-value & (MS - ES) \\
\hline F16 & 4.47 & 1 & 4.54 & 1 & 4.44 & 1 & .371 & .102 \\
F01 & 4.38 & 2 & 4.46 & 2 & 4.35 & 2 & .398 & .114 \\
F17 & 4.28 & 3 & 4.46 & 2 & 4.22 & 3 & .071 & .245 \\
F10 & 4.12 & 4 & 4.30 & 4 & 4.05 & 5 & .560 & .254 \\
F02 & 4.09 & 5 & 4.14 & 6 & 4.07 & 4 & .612 & .071 \\
F03 & 4.07 & 6 & 4.26 & 5 & 3.99 & 7 & .078 & .268 \\
F15 & 3.99 & 7 & 3.90 & 9 & 4.02 & 6 & .417 & -.123 \\
F04 & 3.85 & 8 & 3.66 & 10 & 3.92 & 9 & .108 & -.263 \\
F12 & 3.85 & 8 & 3.98 & 8 & 3.80 & 10 & .278 & .180 \\
F09 & 3.84 & 10 & 4.08 & 7 & 3.75 & 13 & $* .019$ & .326 \\
F06 & 3.82 & 11 & 3.48 & 12 & 3.95 & 8 & $* .006$ & -.474 \\
F14 & 3.73 & 12 & 3.58 & 11 & 3.79 & 11 & .208 & -.212 \\
F18 & 3.63 & 13 & 3.30 & 14 & 3.76 & 12 & .012 & -.462 \\
F05 & 3.51 & 14 & 3.32 & 13 & 3.58 & 16 & .097 & -.257 \\
F11 & 3.51 & 14 & 3.06 & 15 & 3.68 & 14 & $* .000$ & -.617
\end{tabular}




$\begin{array}{lllllllll}\text { F13 } & 3.46 & 16 & 3.00 & 17 & 3.64 & 15 & * .000 & -.638 \\ \text { F08 } & 3.35 & 17 & 3.02 & 16 & 3.48 & 17 & * .002 & -.457 \\ \text { F07 } & 2.96 & 18 & 2.62 & 18 & 3.09 & 18 & * .009 & -.472\end{array}$

Note: The independent samples t-test result, $p$-value that less than 0.05 (p-value $<0.05$ ), indicating the there is a significant difference of the types of staff on the particular factor. P-value with symbol asterisk $(*)$ is the value that less than 0.05 .

The mean ranking analysis result of the variables was shown in Table 2. The result shows that both Managerial staff and Executive Staff agree that the top three most influential factor of the non-adoption of green building specifications are 'Unwillingness to change the conventional way (mean $=4.47)$ ', 'Higher initial cost of green building adoption (mean $=4.38$ )' and 'Low public awareness of environmental issues (mean =4.28)'. Moreover, both types of staff also agree that 'Conflicts with aesthetic issues (mean $=2.96)$ ' is the least influential factor and they also disagree that 'Poor reliability and quality of specifications (mean $=3.35$ )' would have high influences on the non-adoption of green building specifications. Table 2 also showed the result of independent samples t-test among the two groups of respondents. It could be found that there are statistically significance difference between mean scores on the factors 'Incomplete legal framework issues', 'Unfamiliarity with green technologies', 'Inadequate green material supply chain', 'Lack of technology and testing institutes for green specifications', 'Poor reliability and quality of specifications' and 'Conflicts with aesthetic issues.' This may due to the differences in terms of job scopes and tasks assigned in construction projects between the two types of staff, resulting in different perspectives and level of agreements on the factors.

Whereas with regard to the working experience, Table 3 showed that Senior Staff and Junior Staff both have similar perspective on the highest influential and least influential factors of the non-adoption of green building specification, as compared to Table 2, except they have big differences in terms of ranking on few factors. This could be seen from Table 3 that showed that there were statistically significance difference in mean scores among these two different groups on factors 'Low public awareness of environmental issues', 'Lack of market demand on green buildings', 'Unfamiliarity with green technologies', 'Lack of technology innovation', 'Lack of local R\&D institutes and services', 'Inadequate green material supply chain', 'Lack of technology and testing institutes for green specifications', 'Poor reliability and quality of specifications' and 'Conflicts with aesthetic issues'. This may resulted by the differences in terms of working experience and degree of exposure to particular stages of project between Senior Staff and Junior Staff.

Table 3. Mean ranking analysis of the barriers (between junior staff and senior staff)

\begin{tabular}{|c|c|c|c|c|c|c|c|c|}
\hline \multirow[t]{2}{*}{ Code } & \multicolumn{2}{|c|}{ All Respondents } & \multicolumn{2}{|c|}{$\begin{array}{c}\text { Less Than } 5 \text { Years } \\
(<5) \text {, Junior Staff } \\
(J)\end{array}$} & \multicolumn{2}{|c|}{$\begin{array}{c}5 \text { Years and Above } \\
(\geq 5) \text {, Senior Staff } \\
(S)\end{array}$} & \multirow{2}{*}{$\begin{array}{c}\begin{array}{c}\text { Independent } \\
\text { Samples t-Test }\end{array} \\
\text { p-value }\end{array}$} & \multirow{2}{*}{$\begin{array}{c}\begin{array}{c}\text { Mean } \\
\text { Difference }\end{array} \\
(\mathbf{J}-\mathbf{S}) \\
\end{array}$} \\
\hline & Mean & Rank & Mean & Rank & Mean & Rank & & \\
\hline F16 & 4.47 & 1 & 4.37 & 1 & 4.54 & 1 & .102 & -.167 \\
\hline F01 & 4.38 & 2 & 4.35 & 2 & 4.40 & 2 & .635 & -.560 \\
\hline F17 & 4.28 & 3 & 4.12 & 6 & 4.41 & 3 & $* .015$ & -.296 \\
\hline F10 & 4.12 & 4 & 4.09 & 7 & 4.14 & 5 & .694 & -.048 \\
\hline F02 & 4.09 & 5 & 4.13 & 4 & 4.06 & 6 & .561 & .690 \\
\hline F03 & 4.07 & 6 & 3.90 & 12 & 4.20 & 4 & $* .029$ & -.299 \\
\hline F15 & 3.99 & 7 & 4.06 & 8 & 3.93 & 7 & .317 & .133 \\
\hline F04 & 3.85 & 8 & 3.91 & 11 & 3.80 & 10 & .457 & .106 \\
\hline F12 & 3.85 & 8 & 3.85 & 13 & 3.85 & 9 & .959 & -.007 \\
\hline F09 & 3.84 & 10 & 3.77 & 16 & 3.90 & 8 & .294 & -.133 \\
\hline F06 & 3.82 & 11 & 4.15 & 3 & 3.57 & 12 & $* .000$ & .585 \\
\hline F14 & 3.73 & 12 & 3.82 & 14 & 3.67 & 11 & .248 & .154 \\
\hline F18 & 3.63 & 13 & 4.13 & 4 & 3.25 & 14 & $* .000$ & .873 \\
\hline F05 & 3.51 & 14 & 3.79 & 15 & 3.28 & 13 & $* .000$ & .511 \\
\hline F11 & 3.51 & 14 & 3.96 & 10 & 3.16 & 15 & $* .000$ & .805 \\
\hline F13 & 3.46 & 16 & 4.04 & 9 & 3.02 & 17 & $* .000$ & 1.019 \\
\hline F08 & 3.35 & 17 & 3.71 & 17 & 3.08 & 16 & $* .000$ & .627 \\
\hline F07 & 2.96 & 18 & 3.26 & 18 & 2.74 & 18 & $* .001$ & .521 \\
\hline
\end{tabular}

Note: The independent samples t-test result, p-value that less than 0.05 (p-value $<0.05$ ), indicating the there is a significant difference of the types of staff on the particular factor. P-value with symbol asterisk $(*)$ is the value that less than 0.05 .

Besides that, Table 4 showed the result of mean ranking analysis among three groups of respondents who are from different construction firms, included Developer, Consultant and Contractor respectively. From the result, it could be seen that both respondent from Developer and Contractor agreed that 'Unwillingness to change the conventional way' was the most influential factor of the non-adoption of green building specifications, while respondents from Consultant preferred that 'Higher initial cost of green building adoption' was the most influential factor. Whereas, all three groups of respondents agreed that 'Conflicts with aesthetic issues' was the least influential factor to green building specifications 
adoption. Table 4 also showed that there are statistically significance difference in mean scores among these three groups of respondents on factors 'Lack of market demand on green buildings' and 'Lack of technology and testing institutes for green specifications'. This difference is deemed to be caused by the varied nature of these three different construction firms and their respective roles and responsibilities in a construction project.

Moreover, mean ranking analysis was conducted with regards to the three effects caused by the non-adoption of green building specifications and Table 5 showed the result of the analysis. It was found out that the respondents have agreed that 'Worsen soil pollution' is the most significant effect caused by the non-adoption of green building specifications.

Table 4. Mean ranking analysis of the barriers (among developer, consultant and contractor)

\begin{tabular}{cccccccccc}
\hline & \multicolumn{2}{c}{ All Respondents } & \multicolumn{2}{c}{ Developer } & \multicolumn{2}{c}{ Consultant } & \multicolumn{2}{c}{ Contractor } & ANOVA \\
\cline { 2 - 9 } Code & Mean & Rank & Mean & Rank & Mean & Rank & Mean & Rank & p-value \\
\hline F16 & 4.47 & 1 & 4.44 & 1 & 4.41 & 2 & 4.55 & 1 & .505 \\
F01 & 4.38 & 2 & 4.35 & 2 & 4.45 & 1 & 4.34 & 3 & .747 \\
F17 & 4.28 & 3 & 4.24 & 3 & 4.20 & 3 & 4.41 & 2 & .321 \\
F10 & 4.12 & 4 & 4.24 & 3 & 4.12 & 4 & 3.97 & 8 & .154 \\
F02 & 4.09 & 5 & 4.14 & 6 & 4.10 & 5 & 4.02 & 7 & .704 \\
F03 & 4.07 & 6 & 4.20 & 5 & 3.80 & 8 & 4.14 & 4 & $* .048$ \\
F15 & 3.99 & 7 & 3.92 & 9 & 3.96 & 6 & 4.10 & 5 & .491 \\
F04 & 3.85 & 8 & 3.80 & 12 & 3.71 & 12 & 4.03 & 6 & .192 \\
F12 & 3.85 & 8 & 3.99 & 8 & 3.61 & 15 & 3.90 & 9 & .052 \\
F09 & 3.84 & 10 & 4.03 & 7 & 3.71 & 12 & 3.74 & 11 & .057 \\
F06 & 3.82 & 11 & 3.82 & 11 & 3.92 & 7 & 3.74 & 11 & .617 \\
F14 & 3.73 & 12 & 3.86 & 10 & 3.76 & 10 & 3.55 & 15 & .165 \\
F18 & 3.63 & 13 & 3.41 & 14 & 3.80 & 8 & 3.76 & 10 & .085 \\
F05 & 3.51 & 14 & 3.48 & 13 & 3.55 & 16 & 3.50 & 16 & .919 \\
F11 & 3.51 & 14 & 3.28 & 15 & 3.69 & 14 & 3.62 & 13 & .060 \\
F13 & 3.46 & 16 & 3.18 & 17 & 3.73 & 11 & 3.57 & 14 & $* .013$ \\
F08 & 3.35 & 17 & 3.20 & 16 & 3.47 & 17 & 3.43 & 17 & .210 \\
F07 & 2.96 & 18 & 2.92 & 18 & 3.12 & 18 & 2.88 & 18 & .471 \\
\hline
\end{tabular}

Note: The One-way ANOVA result, p-value that less than 0.05 (p-value $<0.05$ ), indicating the there is a significant difference of the types of staff on the particular factor. P-value with symbol asterisk $(*)$ is the value that less than 0.05 .

Table 5. Mean ranking analysis of the effects

\begin{tabular}{lccc}
\hline Effects caused by the non-adoption of green building specifications & Code & Mean & Rank \\
\hline Worsen soil pollution & E03 & 4.21 & 1 \\
Worsen water pollution & E01 & 4.16 & 2 \\
Worsen air pollution & E02 & 3.99 & 3 \\
\hline
\end{tabular}

\section{Factor Analysis}

All the 18 factors were extracted into five factor groupings through factor analysis method and each grouping was given name in accordance to its respective elements, which are Green technology related-factor, Governmental relatedfactor, Economic related-factor, Public awareness and behavior related-factor and Corporate related-factor. Figure 2 showed the factor loadings of each factor in the factor groupings. Green technology related-factor consisted of 'Lack of local R\&D institutes and services', 'Unfamiliarity with green technologies', 'Conflicts with aesthetic issues', Poor reliability and quality of specifications', 'Inadequate green material supply chain', 'Lack of technology and testing institutes for green specifications' and 'Lack of technology innovation'. The second factor grouping, Governmental related-factor comprised of 'Incomplete legal framework issues', 'Lack of governmental regulations and incentives' and 'Lack of benchmarking system'. The third factor grouping, Economic related-factor included 'Higher initial cost of GB adoption', 'Higher cost pressure without the benefits of economies of scale' and 'Lack of market demand on green buildings'. The fourth factor grouping Public awareness and behaviour related-factor encompassed factors 'Lack of knowledge on green technology', 'Unwillingness to change the conventional way' and 'Low public awareness of environmental issues'. The last factor grouping Corporate related-factor consisted of only two factors, which are 'Limited support from the senior management for GS adoptions' and 'Lack of marketisation of specifications'.

The five factor groupings were ranked through their mean scores as well, dividing total mean scores of all the factors in a particular grouping by the number of factors included in respected grouping. Figure 2 showed the average mean scores of each factor grouping. From the figure, it could be seen that Public awareness and behavior related-factor was the highest ranked grouping, followed by Economic-related factor, while Green technology related-factor was the lowest ranked grouping. 


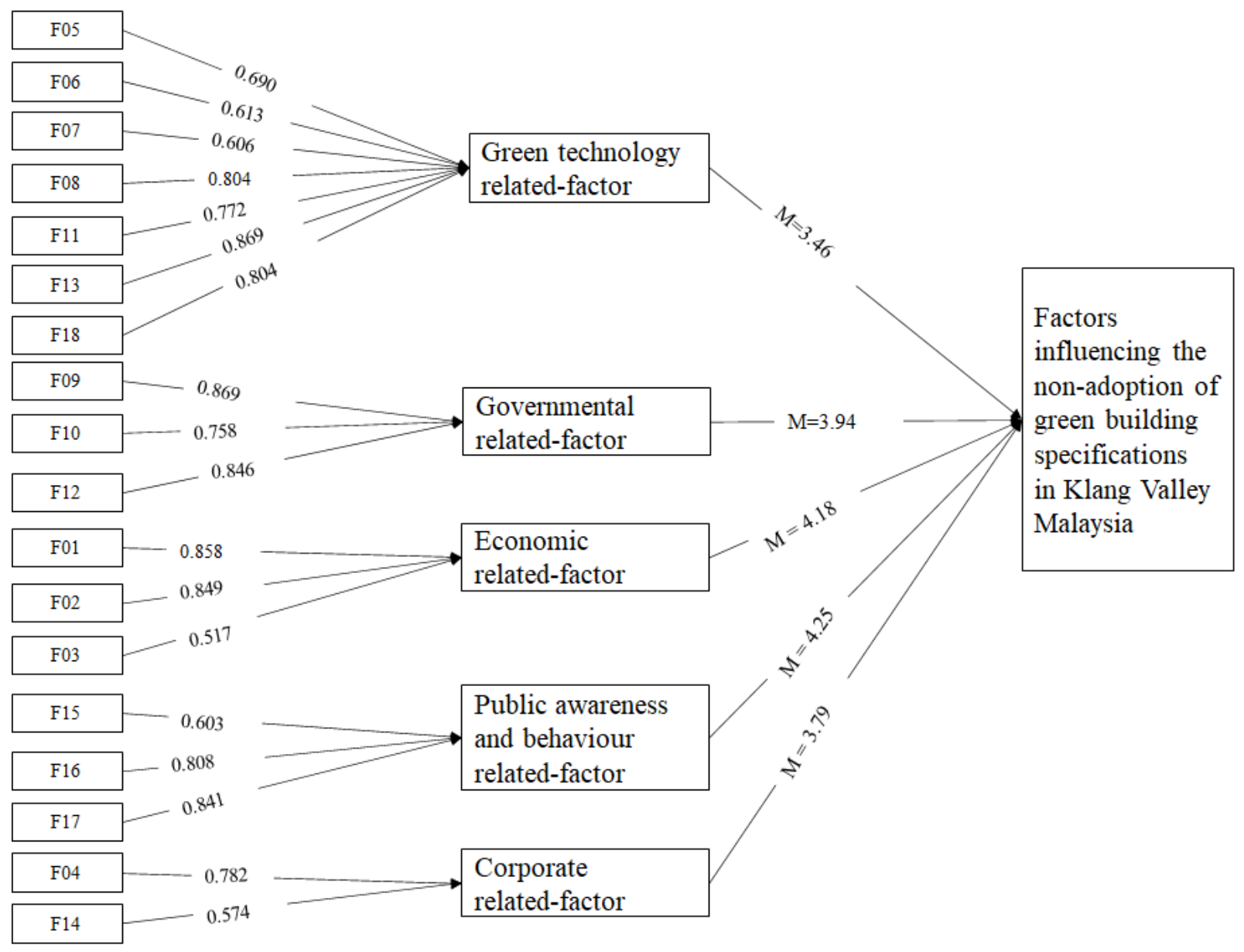

Figure 2. The result of the factor analysis ('M' stands for average mean scores)

\section{Discussion}

According to overall survey result, 'Unwillingness to change conventional way' was ranked as the most influential factor of the non-adoption of green building specifications by the selected respondents. This was because construction stakeholders in Malaysia have traditional mind-set and habitual thinking, as they were unwilling to adopt green practices due to potential risks or uncertainties that may affect their profit return. Therefore, most of the construction stakeholders still preferred conventional way of construction rather than green construction or practices, as those traditional methods were time-tested. This was supported by Darko et al. (2017) who have done similar research and found out that this factor is the highest ranked barrier to green building adoption in United States. However, this result was contrast with another similar study by Wang et al. (2018a), who claiming that this factor was the lowest ranked influential factor of the adoption of green building specifications in China. Thus, it could be inferred that the significance of this factor was varied in accordance to different geographical locations the study conducted.

Next, the second most influential factor as found by this study was 'Higher initial cost of GB (green building) adoption'. This was agreed by most of the respondents as well because initial cost invested in green building specifications was relatively higher compared to conventional specifications. For instance, the initial cost of green building comprised of installation fees of green features (solar panels and water harvesting tank) and procurement of green materials (environmental friendly wall panels or blocks and other eco-friendly construction materials that recognised by Green Label). The initial cost also included GBI (Green Building Index) registration fees and green facilitators' fees. Though the green buildings could reduce life cycle cost by promoting energy and water efficiency, the initial investment undeniably was higher compared to traditional method of construction. This was also supported by Chan et al. (2016) who conducted similar research and gathered opinions from respondents in United States, Australia and Canada. In their research, it showed that this factor is the second highest ranked barrier to the adoption of green building specification. Besides that, similar research that targeted contractor in Sibu, Sarawak, conducted by Ling (2016), also claimed that higher investment cost is the second highest challenge in implementing green building concept.

The third most influential factor in this study is 'Low public awareness of environmental issues'. This may due to the teaching syllabus and materials of Malaysia academic institution lack of highlighting and focusing this topic, resulting public have inadequate knowledge and awareness on such issues. Public played pivotal role in promoting green building specifications as their demands would motivate construction stakeholders to adopt this green practice in order to attract consumers and investors. However, if public have low awareness on the environmental benefits of green building 
specifications, they would not demand developers to implement green building specifications in their housings or factories, thus reducing market demand of such adoption. This result was in line with similar study conducted by Elias and Chong (2015), who claimed this factor was the third highest obstacle to green building implementation.

On the other hand, the least influential factor is 'Conflicts with aesthetic issues' according to the result of the survey. This factor was less concerning by respondents because green building concept unlikely to has conflict with aesthetic appearance of the buildings. For instance, the Energy Commission Diamond Building in Malaysia not only well-known because of the green features installed, but also the polygonal appearance of modernisation presented by this building. Besides this, other green buildings such as The Crystal in London, ACROS Fukuoka Foundation Building in Japan and One Angel Square in UK have also presented pleasure appearances to public despite their green buildings status. This factor was ranked as the least barrier to implement green specifications by Lam et al. (2009) in their research study.

According to the result of this study, the five factor groupings were also ranked in accordance to their mean scores. The selected respondents agree that Public awareness and behavior related-factor is the highest ranked grouping among other factor groupings. This was because the implementation of green building specifications in Malaysia was hindered by the perspectives and attitudes of construction stakeholders towards green practices in the construction industry. Most of them were biased towards the adoption of green building and misinterpreted this adoption would bring risks to their profit return. In addition, they also lack of knowledge with regards to the details or procedures in adopting green construction as well as low awareness on the benefits beneath green building specifications. This may due to academic institutions in Malaysia seldom focused or highlighted knowledge regarding green practices or green construction, resulting construction practitioners in lacking of related knowledge. Therefore, talks or events relating to green building concept should be organised to promote awareness to the construction stakeholders and also to public. Besides that, respondents agree that the second highest ranked factor grouping is Economic related-factor. It was also a significant factor grouping as it was the driving force in inspiring construction stakeholders to adopt sustainability building because it involved the primary consideration of companies, which was cost aspect. Hence, the successfulness of making green building specifications to be ubiquitous relied on the cost and return rate of respective implementation. As the initial cost of green building specifications was higher and the return took longer time to be reaped, all these issues would be an obstacle to construction stakeholders to adopt sustainable practices. Hence, green financing scheme or incentives and allowances should be offered to parties who practiced green building adoptions. In contrast, the selected respondents agree that Green technology related-factor as the least influential factor grouping among all five groupings. This was because green technology in Malaysia has been researched and developed with the aid of related professional bodies such as SIRIM, CIDB and GBC. There were also plenty of accreditations such as Green Label and ISO in Malaysia that aided in quality assurance of building materials. Therefore, this factor grouping would not be a major obstacle to the adoption of green building specifications. The innovation of green technology in Malaysia was also motivated by the manufacturers' intention of reducing material cost as well as increasing marketability of the products. In addition, foreign companies which set up their branches in Malaysia would encourage knowledge transfer and also provided training to local workers, leading to enhancement of green technology development.

\section{CONCLUSION}

It was undeniable that construction activities would bring adverse impacts to the environment by consuming large proportion of natural resources and producing harmful wastes. Hence, the adoption of green building specification s would guarantee sustainable construction (Wang et al., 2018b). This study aimed to demonstrate the challenges to the adoption of green building specifications by researching 18 factors that referred from previous articles. This study implemented online questionnaire to gather responses from selected construction stakeholders and conducted mean ranking analysis to determine the level of significance of the barriers to the adoption of green building specifications. In order to determine the correlation between the factors, factor analysis also conducted for further analysis. The result of this study showed that 'Unwillingness to change the conventional way' as the most influential factor of the non-adoption of green building specifications, in contrast 'Conflicts with aesthetic issues' was the least influential factor. This study also showed the level of significance of the factors from perspectives of different group respondents, in terms of job positions, working experience and types of organisations. Independent samples t-test and one way ANOVA test were conducted to determine the statistically significant difference between the means of various groups of respondents as well. Besides that, the 18 factors were also categorised into five different groupings, which are Green technology related-factor, Economic relatedfactor, Governmental related-factor, Public awareness and behaviour related-factor and Corporate related-factor. In addition, mean ranking analysis conducted on the five factor groupings and the result showed that Public awareness and behaviour related-factor are the highest ranked factor grouping, followed by Economic related-factor and the least ranked is Green technology related-factor.

This study served as guideline for policymakers in Malaysia to promote implementation of green building specifications in this nation. In addition, this study contributed to the construction industry by enhancing construction stakeholders' understanding and knowledge on green building or green construction. This study also recognised the efforts of other researchers by referring their results with this study's findings, in order to show the similarities and differences among the findings. Last but not least, it also acted as the initiator or reference to the scholars in Malaysia to further analyse this field of topic in the future by taking account into more aspects and implementing various research methods. 


\section{REFERENCES}

Chan, A. P. C., Darko, A., Ameyaw, E. E. and Owusu-Manu, D.-G. (2017). Barriers Affecting the Adoption of Green Building Technologies. Journal of Management in Engineering, 33(3), p.04016057. doi: 10.1061/(ASCE)ME.1943-5479.0000507

Darko, A. and Chan, A. P. C. (2016). Review of Barriers to Green Building Adoption. Sustainable Development, 25(3), pp. 167-179. https://doi.org/10.1002/sd.1651

Darko, A., Chan, A. P. C., Ameyaw, E. E., He, B. J. and Olanipekun, A. O. (2017). Examining issues influencing green building technologies adoption: The United States green building experts' perspectives. Energy and Buildings, 140, pp. 320-332. https://doi.org/10.1016/j.enbuild.2017.03.060

Darko, A., Chan, A. P. C., Yang, Y., Shan, M., He, B. J. and Gou, Z. (2018). Influences of barriers, drivers and promotion strategies on green building technologies adoption in developing countries: The Ghanaian case. Journal of Cleaner Production, 200, pp. 687-703. https://doi.org/10.1016/j.jclepro.2018.07.318

Elias, E. M. and Chong, K. L. (2015). The empirical study of green buildings (residential) implementation: perspective of house developers. Procedia Environmental Sciences, 28 pp. 708 - 716. https://doi.org/10.1016/j.proenv.2015.07.083

Hwang, B. G., Zhu, L. and Tan, J. S. H (2017a). Green business park project management: Barriers and solutions for sustainable development. Journal of Cleaner Production, 153, pp. 209-219. https://doi.org/10.1016/j.jclepro.2017.03.210

Hwang, B. G., Zhu, L. and Tan, J. T. M. (2017b). Factors affecting productivity in green building construction projects: The case of Singapore. Journal of Management in Engineering, 33(3). doi: 10.1061/(ASCE)ME.1943-5479.0000499

Hwang, B.-G. and Tan, J. S. (2010). Green building project management: obstacles and solutions for sustainable development. Sustainable Development, 20(5), pp.335-349. https://doi.org/10.1002/sd.492

Lam, P. T. I., Chan, E. H. W., Chau, C. K., Poon, C. S. and Chun, K. P. (2009). Integrating Green Specifications in Construction and Overcoming Barriers in Their Use. Journal of Professional Issues in Engineering Education and Practice, 135(4), pp.142-152. doi: 10.1061/(ASCE)1052-3928(2009)135:4(142)

Ling, N. N., (2016). The Challenges in Implementing Green Building Concept - A Study among Contractors in Sibu, Sarawak

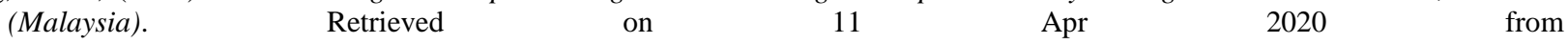
https://www.academia.edu/35352719/THE_CHALLENGES_IN_IMPLEMENTING_GREEN_BUILDING_CONCEPT_A_ST UDY_AMONG_CONTRACTORS_IN_SIBU_SARAWAK_MALAYSIA_LING_NENG_NIIG_BSC_HONS_QUANTITY_S URVEYING_AND_COST_MANAGEMENT_3_0_SCHOOL_OF_BUILT_ENVIRONMENT

Potbhare, V., Syal, M. and Korkmaz, S. (2009). Adoption Of Green Building Guidelines In Developing Countries Based On U.S. And India Experiences. Journal of Green Building, 4(2). doi: 10.3992/jgb.4.2.158

Samari, M., Esmaeilifar, R., Ghodrati, M. and Mohd Shafiei, M. W. (2013). The Investigation of the Barriers in Developing Green Building in Malaysia. Modern Applied Science, 7(2). doi: 10.5539/mas.v7n2p1

Shi, Q., Zuo, J., Huang, R., Huang, J. and Pullen, S. (2013). Identifying the critical factors for green construction - An empirical study in China. Habitat International, 40, pp. 1-8. https://doi.org/10.1016/j.habitatint.2013.01.003

Simpeh, E. K. and Smallwood, J. J. (2015). Factors influencing the growth of green building in the South African construction industry. In J Gibberd (Ed.) and D C U Conradie (Ed.) Proceedings of the Smart and Sustainable Built Environment (SASBE) Conference 2015 (pp. 303-310). Pretoria, South Africa: University of Pretoria.

Wang, W., Zhang, S. and Pasquire, C. (2018a). Factors for the adoption of green building specifications in China. International Journal of Building Pathology and Adaptation,36, pp. 254-267. doi: 10.1108/IJBPA-06-2017-0027

Wang, W., Zhang, S., Su, Y. and Deng, X. (2018b). Key Factors to Green Building Technologies Adoption in Developing Countries: The Perspective of Chinese Designers. Sustainability, 10(11), p.4135. doi: 10.3390/su10114135

\section{ACKNOWLEDGEMENT}

This research was supported by Universiti Tunku Abdul Rahman, Sungai Long Campus, Malaysia. The authors would like to thank Assistant Professor Dr Felicia Yong Yan Yan for her suggestions on preparing the manuscript.

\section{DECLARATION OF CONFLICT OF INTEREST}

The authors declare that there is no conflict of interest regarding the publication of this paper.

\section{AUTHORS' BIOGRAPHY}

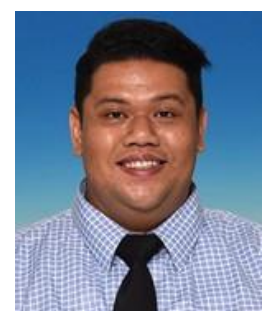

Mohd Hilmi Izwan Abd-Rahim is an Assistant Professor in Lee Kong Chian Faculty of Engineering and Science at Universiti Tunku Abdul Rahman, Sungai Long Campus, Malaysia. He received his PhD (Technology Management), MSc (Technology Management), and Bachelor of Technology Management (Hons) (Construction Management) from Universiti Tun Hussein Onn Malaysia. 


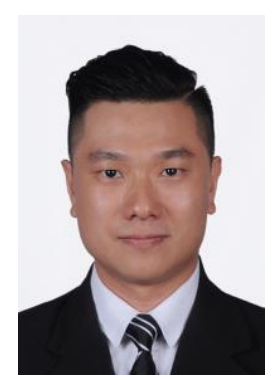

Tien-Choon Toh is an Assistant Professor in Lee Kong Chian Faculty of Engineering and Science at Universiti Tunku Abdul Rahman, Sungai Long Campus, Malaysia. He received his PhD (Quantity Surveying), MSc (Construction Management), BSc (Hons) (Construction), and Dip in Quantity Surveying from Universiti Teknologi Malaysia.

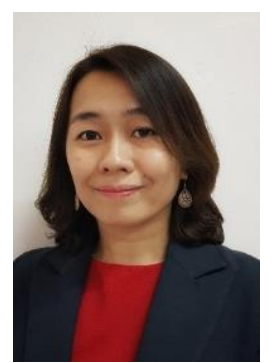

Yoke-Lian Lew is an Assistant Professor in Lee Kong Chian Faculty of Engineering and Science at Universiti Tunku Abdul Rahman, Sungai Long Campus, Malaysia. She received her PhD (Project Management), MSc (Project Management) and BEng (Hons) (Civil) from Universiti Putra Malaysia, and Dip in Civil Engineering from Politeknik Ungku Omar.

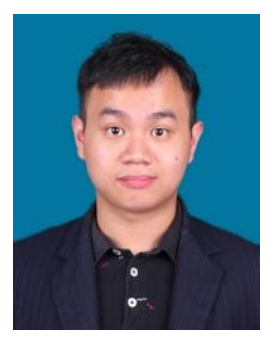

See-Jie $\mathrm{Ng}$ is a Former Undergraduate Student in Lee Kong Chian Faculty of Engineering and Science at Universiti Tunku Abdul Rahman, Sungai Long Campus, Malaysia. He received his BSc (Hons) (Quantity Surveying) from Universiti Tunku Abdul Rahman.

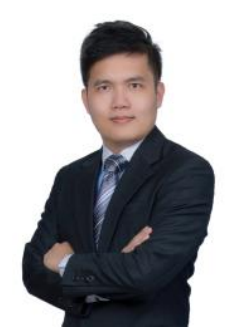

Kai-Chen Goh is an Associate Professor in Faculty of Technology Management and Business at Universiti Tun Hussein Onn Malaysia, Malaysia. He received his PhD (Built Environment and Engineering) from Queensland University of Technology, and MSc (Construction Management), BSc (Hons) (Construction) and Dip in Quantity Surveying from Universiti Teknologi Malaysia.

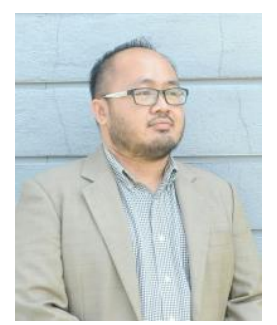

Sulzakimin Mohamed is a Lecturer in Faculty of Technology Management and Business at Universiti Tun Hussein Onn Malaysia, Malaysia. He received his PhD (Technology Management) from Universiti Tun Hussein Onn Malaysia, MSc (Construction Management) from Glasgow Caledonian University, BSc (Hons) (Surveying and Mapping Sciences) from University of East London, and Dip in Land Surveying from Institut Teknologi MARA. 
Nadzirah Zainordin is a Senior Lecturer in Faculty of Engineering, Built Environment and Information Technology at SEGi University, Malaysia. She received her MSc (Quantity Surveying) from Heriot-Watt University and BSc (Hons) (Quantity Surveying) from Twintech International University College of Technology.

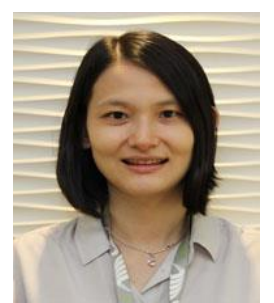

Mei-Ye Kho is a Senior Lecturer in Faculty of Built Environment at Universiti Malaya, Malaysia. She received her PhD (Architecture and Surveying), MSc (Building), and Bachelor of Quantity Surveying (Hons) from Universiti Malaya. 